\title{
May preablative thyroglobulin level be a prognostic indicator for papillary thyroid cancer?
}

\author{
Elgin Ozkan ${ }^{*}$, Cigdem Soydal ${ }^{1}$, Mine Araz $^{1}$, Yasemin Genc ${ }^{2}$ and Nuriye Ozlem Kucuk ${ }^{1}$ \\ ${ }^{1}$ Ankara University Medical School, Department of Nuclear Medicine, Turkey \\ ${ }^{2}$ Ankara University Medical School, Department of Biostatistics, Turkey
}

\begin{abstract}
Aim: To investigate the effect of preablative thyroglobulin $(\mathrm{Tg})$ levels without L-thyroxine (T4) suppression ( $\mathrm{Tg}$-off) on prognosis together with other risk factors in a large, long-term followed-up papillary thyroid cancer patient group.

Materials and methods: A total of 212 PTC patients were included to the study. All the patients underwent total or near-total thyroidectomy. Serum thyroid stimulating hormon (TSH) and Tg-off levels were obtained before radioiodine ablation. After radioiodine treatment, patients were followed-up by serum Tg measurements (under and off T4 suppression), I-131 whole body scintigraphy (wbs), neck ultrasonography (USG) and neck or thorax computerized tomography (CT). Mean follow-up time was 6.2 years (range: 3-17 years). In addition to well-known risk factors such as age, sex, tumor size, capsule invasion, vascular invasion, lymph node metastasis, serum preablative Tg-off levels of the patients were also noted. For statistical analysis, a single variable called 'risk status' representing the combination of three risk factors (capsule invasion, vascular invasion and lymph node metastasis) was defined.

Results: Recurrence was detected in 14 of 212 (6.6\%) patients. In the univariate analysis, among the disease-related variables, tumor size ( $\mathrm{p}=0.002)$, capsule invasion $(\mathrm{p}=0,001)$, lymph node metastasis $(\mathrm{p}=0.015)$ and risk status $(\mathrm{p}=0.000)$ were significantly associated with recurrence. However, vascular invasion ( $\mathrm{p}=0,176)$ and preablative Tg-off $(p=0,514)$ were not associated with recurrence. In the multivariate analysis, tumor size ( $p=0,013)$ and risk status ( $p=0,002)$ was associated with recurrence but preablative $\mathrm{Tg}$-off was not significantly associated. However, if the relation between preablative Tg-off and recurrence was studied in two different groups (low risk and high risk), it was found that in the low risk group there was no significant relation between the recurrence rates and increasing preablative $\mathrm{Tg}$-off levels $\left(\chi^{2}=0.241, p=0,623\right)$, but in the high risk group, although it was not statistically significant, there was a trend to raise in the recurrence rates with the increasing preablative Tg-off levels $\left(\chi^{2}=3.482, \mathrm{p}=0,062\right)$.
\end{abstract}

Conclusion: In this retrospective study where a large long-term followed-up papillary thyroid cancer patient group was included, it is founded that preablative Tg-off value is not a statistically important prognostic risk factor when compared to the other risk factors.

\section{Introduction}

Well differentiated papillary carcinoma accounts for approximately $90 \%$ of thyroid cancers [1]. Well differentiated thyroid cancer (DTC) has a quite well prognosis with $85-93 \% 10$ year survival rates [2]. Therapy of DTC is surgery and then radioactive iodine treatment. The aim of the radioiodine therapy is the ablation of the possible residual thyroid tissue after surgery and detection of metastatic foci. After surgery and radioiodine ablation, serum thyroglobulin $(\mathrm{Tg})$ levels is an important marker in the follow-up of the disease. The high specificity of $\mathrm{Tg}$ depends on the fact that the only source of $\mathrm{Tg}$ in the human body is the thyroid parenchymal cells. The presence of Tg after total thyroidectomy and radioiodine ablation is an indicator for persistent disease or recurrence. Especially, progressive increase in the Tg levels is an early and real marker for recurrent disease [3]. It has been reported that the Tg levels measured 6 or 12 months later than the radioiodine ablation without L-thyroxine (T4) supression (Tg-off) is an important parameter for detection of disease progression risk [4-6].

Moreover, in the literature, there are many studies investigating the role of preablative Tg levels in the clinical management of DTC. Some investigators reported that preablative $\mathrm{Tg}$ levels could be a predictor for progressive or metastatic disease in the long term follow-up period and could be regarded as another criterion together with lymph node invasion for choosing high risk patients [7-10]. Despite this, preablative
Tg level is not as frequently used as postablative Tg level in the clinical practice.

The results of the Surveillance, Epidemiology and End Results programme of the National Cancer Institute [11] and National Cancer Database [2] showed that risk factors affecting prognosis in DTC are age, sex, tumor size, histopathological type and grade, local invasion, multicentricity and distant metastasis. Based on these prognostic indicators, many scoring or grading systems have been created within the last 20 years. In the recent guidelines published by the American Thyroid Association (ATA) [12], European Thyroid Association (ETA) [13] and British Thyroid Association (BTA) [14], patients are divided into risk groups for the possibility of recurrence based primarily on age, tumor size, presence of nodal invasion and metastasis. However, preablative $\mathrm{Tg}$ levels were not taken into consideration and its effect on

Correspondence to: Elgin OZKAN, Ankara University Medical School, Department of Nuclear Medicine, Dikimevi, Ankara/TURKEY, Tel: +90 312562 01 98; Fax: +90 31236208 97; E-mail: ozkanelgin@yahoo.com

Key words: papillary thyroid carcinoma, preablative thyroglobulin, prognosis, risk factors

Received: January 13, 2017; Accepted: February 06, 2017; Published: February 09,2017 
prognosis was not mentioned in any of these guidelines.

The aim of this study was to investigate the effect of preablative Tg-off levels on prognosis together with other risk factors in a large, long-term followed-up papillary thyroid cancer (PTC) patient group.

\section{Material and method}

\section{Patients}

Between 1993 and 2009 years, 508 PTC patients who underwent radioiodine ablation in our clinic were reviewed. Two hundred and ninety-six patients who had high levels of antithyroglobulin antibody, distant metastasis or macroscopic residuel thyroid tissue at the beginning of the treatment and who could not be followed-up regularly were excluded. In the remaining 212 PTC patients ( 177 F, $35 \mathrm{M}$; mean age: $49.8 \pm 12.9 \mathrm{y}$ ) were included in the study. In addition to well-known risk factors such as age, sex, tumor size, capsule invasion, vascular invasion, lymph node metastasis, serum Tg-off levels of all the patients were also identified. Furthermore, results of performed diagnostic tools; ultrasonography (USG), neck or thorax computerized tomography (CT), I-131 whole body scintigraphy (wbs), serum Tg measurements (under and off T4 suppression) were evaluated. Additional surgical procedures (lymph node dissection) and radioiodine treatments (doses and numbers) were also taken into consideration. We classified the patients into two groups; high risk who have at least one of these histopathological criteria (capsule invasion, vascular invasion, lymph node metastasis) and low risk who have none of them.

All patients had undergone radioiodine ablation following total or near-total thyroidectomy. Diagnostic scintigraphy was not performed before ablative doses in order to prevent the stunning effect. Serum TSH and Tg-off measurements were obtained on the same day before the radioiodine therapy. I-131 was applied if the TSH level was higher than $30 \mathrm{IU} / \mathrm{mL}$. The doses of radioiodine was determined according to fixed dose protocol, 1850-3700 MBq for low risk group and 4625-5550 $\mathrm{MBq}$ for high risk group. T4 supression treatment was started after 48 hours of radioiodine ablation treatment.

At the $3^{\text {rd }}$ month of ablation therapy, serum TSH and Tg levels were checked under T4 suppression. At the $6^{\text {th }}$ month of therapy, I-131 wbs with $185 \mathrm{MBq}$ radioiodine was performed with measurement of serum TSH and Tg levels at the T4 off state. The next steps of the follow-up procedure were specified individually, depending on the risk factors of the patients by the measurement of Tg levels, I-131 wbs, neck USG, neck or thorax CT.

Serum Tg levels were measured by using a commercial immunoradiometric assay (IMMULITE Systems, EURO/DPC Ltd; Normal range was 1.6-59.9 ng/ml) until 2005. After 2005, serum Tg measurements were done with immunoassay method. (Beckman Access Systems Thyroglobulin assay, BECKMAN COULTER Ltd; Normal range was $1.15-35 \mathrm{ng} / \mathrm{ml}$ ).

\section{Statistical analysis}

Continuous data are presented as the mean \pm standard deviation (SD), median, and ranges, and categorical data are expressed as the frequency and proportions. The analyses were performed in two steps. First, the independent variables were entered into the logistic model one by one. Then, to determine the independent risk indicators of having reccurence, we performed a multiple logistic regression following the Hierarchical Backward Elimination Approach. All variables with $\mathrm{p}$ values less than 0.25 in univariate analysis were included in multivariate analysis. The analyses were performed using the SPSS software, version

\subsection{0 (SPSS Inc.,Chicago, Illinois, USA).}

\section{Results}

In all our patients with papillary thyroid cancer, mean tumor size was calculated as $14.4 \pm 5.9 \mathrm{~mm}$ (range $5-45 \mathrm{~mm}$ ). However, $158 / 212$ (74.5\%) patients had a tumor size $\leq 10 \mathrm{~mm}$. Capsular invasion, vascular invasion and lymph node metastasis have been seen in 41/212 (19.3\%), $4 / 212(1.9 \%)$ and $19 / 212$ (9\%) patients, respectively. In the detailed evaluation of the patients according to risk status, 159 of the 212 (75\%) patients were in the low risk and the rest of the patients were in the high-risk groups. Radioiodine treatment was applied as a mean 3570 $\pm 447.7 \mathrm{MBq}$ in the low risk group and a mean $4713 \pm 773 \mathrm{MBq}$ in the high-risk group. Mean follow-up time was 6.2 years (range: 3-17 years). Mean preablative Tg-off level was found $7.57 \mathrm{ng} / \mathrm{ml}$ (range: $0.01-602$ $\mathrm{ng} / \mathrm{ml}$ ). Preablative Tg-off levels were measured 1-2 months later than the operation. When the patients were classified according to their preablative Tg-off levels as Tg $<5 \mathrm{ng} / \mathrm{ml}, \mathrm{Tg}: 5-10 \mathrm{ng} / \mathrm{ml}$ and $\mathrm{Tg}>10 \mathrm{ng} /$ $\mathrm{ml}, 86 / 212$ (40.6\%), 32/212 (15.1\%) and 94/212 (44.3\%) patients were found in each group respectively. The characteristics of the 212 patients are shown in Table 1.

During the follow-up period, recurrence was detected in 14 of 212 (6.6\%) patients. Lymph node metastasis in 10 patients, recurrence in the thyroid bed in 3 patients and lung metastases in one patient were determined. $4 / 14$ patients who had recurrence was in the low risk group (preablative Tg-off values $<5 \mathrm{ng} / \mathrm{ml}$ in two, $5-10 \mathrm{ng} / \mathrm{ml}$ in one and $>10$ $\mathrm{ng} / \mathrm{ml}$ in one), $10 / 14$ patients was in the high risk group (preablative Tg-off values $<5 \mathrm{ng} / \mathrm{ml}$ in one, $5-10 \mathrm{ng} / \mathrm{ml}$ in one and $>10 \mathrm{ng} / \mathrm{ml}$ in eight). When the separate univariate logistic models were used to

Table 1. Characteristics of patients.

\begin{tabular}{|c|c|}
\hline & Statistics $(n=212)$ \\
\hline Age, Mean \pm SD (Range) & $49.8 \pm 12.9(13-84)$ \\
\hline$<45$ years & $60(28.3)$ \\
\hline$\geq 45$ years & $152(71.7)$ \\
\hline \multicolumn{2}{|l|}{ Sex, n (\%) } \\
\hline Female & $177(83.5)$ \\
\hline Male & $35(16.5)$ \\
\hline Tumor Size, Mean \pm SD (Range) & $14.4 \pm 5.9(5-45)$ \\
\hline \multicolumn{2}{|l|}{ Tumor Size, n (\%) } \\
\hline$\leq 10 \mathrm{~mm}$ & $158(74.5)$ \\
\hline$>10 \mathrm{~mm}$ & $54(25.5)$ \\
\hline \multicolumn{2}{|l|}{ Capsule Invasion, n (\%) } \\
\hline No & $171(80.7)$ \\
\hline Yes & $41(19.3)$ \\
\hline \multicolumn{2}{|l|}{ Vascular Invasion, n (\%) } \\
\hline No & $208(98.1)$ \\
\hline Yes & $4(1.9)$ \\
\hline \multicolumn{2}{|l|}{ Lymph Node Metastasis, n (\%) } \\
\hline No & $193(91)$ \\
\hline Yes & $19(9)$ \\
\hline \multicolumn{2}{|l|}{ Risk Status*, n (\%) } \\
\hline Low & $159(75)$ \\
\hline High & $53(25)$ \\
\hline Preablative Tg, Median (Range) & $7.57(0.01-602)$ \\
\hline \multicolumn{2}{|l|}{ Preablative Tg levels, n (\%) } \\
\hline$<5 \mathrm{nq} / \mathrm{ml}$ & $86(40.6)$ \\
\hline $5-10 \mathrm{nq} / \mathrm{ml}$ & $32(15.1)$ \\
\hline$>10 \mathrm{nq} / \mathrm{ml}$ & $94(44.3)$ \\
\hline
\end{tabular}

*Patients who have at least one of these histopathological criteria (capsule invasion, vascular invasion, lymph node metastasis) were classified as high risk patients. 
analyze the independent variables one by one, there were statistically significant associations among recurrence, the outcome variable, and several independent variables. Table 2 gives the odds ratios $(\mathrm{OR})$ and corresponding $95 \%$ confidence intervals (CI) for each demographic (age, sex) and disease-related variables. In current study according to Table 2, there was no difference between sex and age groups. Among the disease-related variables, tumor size, capsule invasion, lymph node metastasis and risk status were significantly associated with recurrence. However, vascular invasion and preablative Tg-off levels were not associated with recurrence.

In this study, patients who have at least one of these histopathological criteria were classified as high-risk patients: capsular invasion, vascular invasion and lymph node metastasis. For this reason, there is a statistical relationship between these three risk factors and variable defined as "risk status". Because the dependent variables cannot be included to multivariate logistic regression analysis, the risk status representing both three variables was used for the multivariate analysis. Tumor size and preablative Tg-off, the variables which had $\mathrm{p}$ values $<0.25$ in the univariate analysis were also added to the multivariate analysis.

In the multivariate logistic regression model presented in Table 3, the effects of the risk factors were estimated simultaneously and the effect associated with each factor was therefore adjusted depending

Table 2. Univariate Logistic Regression Analyses for individual risk factors of recurrence.

\begin{tabular}{|c|c|c|c|c|}
\hline \multirow[b]{2}{*}{ Risk Factors } & \multicolumn{2}{|c|}{ Recurrence } & \multicolumn{2}{|c|}{ Univariate analysis } \\
\hline & $\begin{array}{c}\text { Yes } \\
\text { n (\%) }\end{array}$ & $\begin{array}{c}\text { No } \\
\text { n (\%) }\end{array}$ & OR $(95 \% \mathrm{CI})$ & $\mathrm{p}$ \\
\hline \multicolumn{5}{|l|}{ Age (years) } \\
\hline$<45$ & $4(6.7)$ & $56(93.3)$ & 1(Ref) & \\
\hline$\geq 45$ & $10(6.6)$ & $142(93.4)$ & $0.9(0.3-3.3)$ & 0.982 \\
\hline \multicolumn{5}{|l|}{ Sex } \\
\hline Female & $11(6.2)$ & $166(93.8)$ & 1(Ref) & \\
\hline Male & $3(8.6)$ & $32(91.4)$ & $1.4(0.4-5.4)$ & 0.610 \\
\hline \multicolumn{5}{|c|}{ Tumor Size (mm) } \\
\hline$\leq 10$ & $5(3.2)$ & $153(96.8)$ & 1(Ref) & \\
\hline$>10$ & $9(16.7)$ & $45(83.3)$ & $6.1(1.9-19.2)$ & 0.002 \\
\hline \multicolumn{5}{|l|}{ Capsule Invasion } \\
\hline No & $6(3.5)$ & $165(96.5)$ & 1(Ref) & \\
\hline Yes & $8(19.5)$ & $33(80.5)$ & $6.7(2.1-20.5)$ & 0.001 \\
\hline \multicolumn{5}{|c|}{ Vascular Invasion } \\
\hline No & $13(6.3)$ & $195(93.8)$ & 1(Ref) & \\
\hline Yes & $1(25)$ & $3(75)$ & $5(0.5-51.5)$ & 0.176 \\
\hline \multicolumn{5}{|c|}{ Lymph Node Metastasis } \\
\hline No & $10(5.2)$ & $183(94.8)$ & 1(Ref) & \\
\hline Yes & $4(21.1)$ & $15(78.9)$ & $4.8(1.4-17.4)$ & 0.015 \\
\hline \multicolumn{5}{|l|}{ Risk Status } \\
\hline Low & $4(2.5)$ & $155(97.5)$ & 1(Ref) & \\
\hline High & $10(18.9)$ & $43(81.1)$ & $9(2.7-30.2)$ & 0.000 \\
\hline \multicolumn{5}{|c|}{ Preablative Tg levels } \\
\hline$<5 \mathrm{nq} / \mathrm{ml}$ & $3(3.5)$ & $83(96.5)$ & 1(Ref) & \\
\hline $5-10 \mathrm{nq} / \mathrm{ml}$ & $2(6.3)$ & $30(93.8)$ & $1.8(0.3-11.6)$ & 0.514 \\
\hline$>10 \mathrm{nq} / \mathrm{ml}$ & $9(9.6)$ & $85(90.4)$ & $2.9(0.8-11.2)$ & 0.116 \\
\hline
\end{tabular}

OR; Odds Ratio, CI; Confidence Interval on the influence of the other variables in the model. Multivariate logistic regression analysis was slightly different from the results of univariate analyses. In the final model, tumor size remained significantly associated with the recurrence. Patients who have $>10$ $\mathrm{mm}$ tumor was more likely to have recurrence than patiens with $\leq 10$ $\mathrm{mm}$ tumor size $(\mathrm{OR}=4.5, \mathrm{p}=0.013)$. Not surprisingly, risk status was the most significant indicator associated with recurrence. Patients having high risk had a significantly higher risk of recurrence compared with patients having low risk $(\mathrm{OR}=7.1, \mathrm{p}=0.002)$ (Table 3). Pre-ablative Tgoff was not significantly associated with recurrence.

In the regression analysis, preablative Tg-off levels were not to be related with recurrence. However, if the relation between preablative Tg-off levels and recurrence was studied in two different groups (low risk and high risk), it was found that in the low risk group there was no significant relation between the recurrence rates and increasing Tg-off levels $\left(\chi^{2}=0.241, p=0,623\right)$, but in the high risk group, although it was not statistically significant, there was a trend to raise in the recurrence rates with the increasing Tg-off levels $\left(\chi^{2}=3.482, p=0,062\right)$ (Table 4$)$.

\section{Discussion}

Age, sex, tumor size, histological type and grade, local invasion, multicentricity and metastases have been defined as well-known prognostic risk factors of DTCs [2,11]. In this study, tumor size, capsule invasion, lymph node metastasis and risk status have been found to be risk factors to affect disease prognosis.

Age at diagnosis has been described as a strong prognostic factor $[2,11,15-17]$. It has been reported that recurrence and death rates linearly increase after the age of forty-five [18]. Therefore it has been thought that, age-related risk increase might be related to the fact that these patients generally have aggressive histological tumor variants at presentation with locally aggressive behavior and a high incidence of distant metastasis. However, this explanation seems insufficient to explain why children have very good long-term prognosis despite having extensive disease, high incidence of lymph node metastasis and recurrent disease [19-21]. Since age appears not to be an independent risk factor, some authors suggested that age should be considered together with multiple age-related factors such as nutrition, immune

Table 3. Multivariate Logistic Regression Analyses for risk factors of recurrence.

\begin{tabular}{|c|c|c|}
\hline \multirow[b]{2}{*}{ Risk Factors } & \multicolumn{2}{|c|}{ Multiple analysis } \\
\hline & OR $(95 \% \mathrm{CI})$ & $\mathrm{p}$ \\
\hline \multicolumn{3}{|c|}{ Tumor Size (mm) } \\
\hline$\leq 10$ & 1(Ref) & \\
\hline$>10$ & $4.5(1.4-14.9)$ & 0.013 \\
\hline \multicolumn{3}{|l|}{ Risk Status } \\
\hline Low & 1(Ref) & \\
\hline High & $7.1(2.1-24.5)$ & 0.002 \\
\hline
\end{tabular}

OR; Odds Ratio, CI; Confidence Interval

Table 4. Preablative Tg and recurrence relation in the risk status groups.

\begin{tabular}{|c|c|c|c|c|c|}
\hline \multirow[b]{2}{*}{$\begin{array}{c}\text { Risk } \\
\text { Status }\end{array}$} & \multirow[b]{2}{*}{$\begin{array}{c}\text { Preablative } \\
\mathrm{Tg}, \mathrm{nq} / \mathrm{ml}\end{array}$} & \multicolumn{2}{|c|}{ Recurrence } & \multirow[b]{2}{*}{$\chi^{2}$} & \multirow[b]{2}{*}{$\mathbf{p}$} \\
\hline & & $\begin{array}{c}\text { Yes } \\
\text { n (\%) }\end{array}$ & $\begin{array}{c}\text { No } \\
\text { n (\%) }\end{array}$ & & \\
\hline \multirow[t]{3}{*}{ Low } & $<5$ & $2(2.9)$ & $68(97.1)$ & \multirow{3}{*}{0.241} & \multirow{3}{*}{0,623} \\
\hline & $5-10$ & $1(4.3)$ & $22(95.7)$ & & \\
\hline & $>10$ & $1(1.5)$ & $65(98.5)$ & & \\
\hline \multirow[t]{3}{*}{ High } & $<5$ & $1(6.3)$ & $15(93.8)$ & \multirow{3}{*}{3.482} & \multirow{3}{*}{0,062} \\
\hline & $5-10$ & $1(11.1)$ & $8(88.9)$ & & \\
\hline & $>10$ & $8(28.6)$ & $20(71.4)$ & & \\
\hline
\end{tabular}


status, DNA repair ability, effect of genetic mutations. On the other hand, no difference has been seen in the survival rates of the patients at same age and same stage of the disease [11]. In our study, we did not find a relationship between the age of the patients and the disease prognosis. This situation might be explained by low recurrence rate of our study which might be as a result the patients with extensive disease at the presentation were not included in the study.

Sex is one of the other prognostic factors of DTC $[2,11,17,22]$. No relationship between sex and prognosis was found in our study. Similarly, some authors have failed to show that sex is an independent prognostic factor $[19,20]$. In conclusion, sex has not been accepted as a strong risk factor $[11,15]$.

The other described risk factor in predicting disease prognosis is tumor histology $[1,2,11,16,22-23]$. As known, papillary thyroid carcinoma is the most common histological subtype that generally has good outcomes [24]. However, follicular thyroid carcinoma has been described with poor prognosis [25-27]. Because only papillary thyroid carcinoma subtype was included in our study, we investigated prognostic risk factors of just this histologic subtype not follicular type. It is known that histological variant is the one of the important risk factors for papillary thyroid carcinomas [18]. But, since the patients had undergone thyroidectomy in different hospitals and pathologic examinations had performed by different pathologists, we could not reach enough detailed information about pathological results. For this reason it was not possible to compare the prognosis of different histopathological subtypes of papillary thyroid cancer.

Tumor size is another well-known prognostic factor and also it has been reported that a tumor size larger than $4 \mathrm{~cm}$ and extrathyroidal invasion are poor prognostic factors [1,2,11,16,22,24]. Disease prognosis gets worse while tumor size becomes larger in both the papillary and follicular thyroid carcinomas. In our study, in both the univariate and multivariate analyses, we found a statistically significant correlation between tumor size and recurrence incidence. Although recurrence rate of patients with tumor size less than $1 \mathrm{~cm}$ is low, interestingly 5 out of 14 (35\%) patients with recurrent disease had microcarcinoma.

It is believed that there is no prognostic importance of regional lymph node metastasis in papillary thyroid cancer patients. However, recent studies have showed that presence of lymph node metastasis is related to high recurrence rate and in older patients associated with increased disease related death risk [28-30]. Similarly, we found a statistically significant relationship between presence of lymph node metastases at the presentation and recurrence rate.

Extracapsular invasion at the presentation is a real prognostic parameter for both papillary and follicular thyroid carcinomas $[2,11,17]$. Although presence of extracapsular invasion is common in papillary thyroid carcinomas, especially in poor prognostic histological subtypes, vascular invasion is not very common [24,31]. In our study, it has been seen that presence of extracapsular invasion is related to high recurrence rates which is compatible with current literature. Similarly, we have seen a low rate of vascular invasion which was not associated with recurrence disease in the univarite analysis. Our general treatment approach is to apply higher doses of radioiodine to patients with presence of least one of these criteria: extracapsular invasion, vascular invasion and lymph node metastasis. Additionally we interpreted the disease recurrence rates of patients by classifying them according to risk status. Not surprisingly, in multivariate analysis, we have detected that risk status is an important parameter for recurrent disease.
In our study, additional to well-known risk factors, the contribution of preablative Tg-off levels to the disease prognosis was evaluated. The importance of preablative Tg levels is controversial because of presence of remnant thyroid tissue. In a few studies, it has been reported that there might be a correlation between preablative Tg levels and presence of metastatic or recurrent disease $[8,32,33]$. Toubeau et al. showed that although not as important as postablative $\mathrm{Tg}$, preablative $\mathrm{Tg}$ levels might be helpful to predict disease prognosis of DTC. They recommended that patients with lymph node metastases or high preablative Tg levels at the presentation should be followed-up carefully [10]. Hall et al. reported that high tumor stage at diagnosis) and Tg-off levels, higher than $20 \mathrm{ng} / \mathrm{ml}$, which was measured at the postoperative $3 \mathrm{rd}$ month, might be a predictor for disease recurrence [32]. Similarly, Lin et al. showed that postoperative serum Tg levels, greater than or equal to $10 \mathrm{ng} / \mathrm{ml}$, are a useful marker to predict prognosis in patients with papillary and follicular thyroid cancer [33]. Different from literature, in our study, any relationship between preablative Tg-off levels and recurrence rate was not found in both univariate and multivariate analyses. It might be because a small numbers of patients developed recurrent disease. In the detailed analysis of patients according to disease stage, while a correlation between preablative Tg-off levels and the recurrence rates of low risk group was not found, a correlation in high risk group was seen which was not statistically significant but very close to significance limit. Recently, it has been claimed that some of low risk stratified patients might be followed-up without applying radioiodine ablation treatment and in this case, preablative Tg levels could be helpful in selecting suitable patients [34-36]. Therefore, in our study, the disease recurrence has been seen in two patients with a preablative Tg-off level under $5 \mathrm{ng} / \mathrm{ml}$ in low risk group. For this reason, we believe that radioiodine treatment should be given even in this low risk patient group.

As a conclusion, in this retrospective study where a large long-term followed-up papillary thyroid cancer patient group was included, it is founded that preablative $\mathrm{Tg}$-off value is not a statistically important prognostic risk factor when compared to the other risk factors.

\section{References}

1. Eustatia-Rutten CF, Corssmit EP, Biermasz NR, Pereira AM, Romijn JA, et al. (2006) Survival and death causes in differentiated thyroid carcinoma. J Clin Endocrinol Metab. 91: 313-319.

2. Hundahl SA, Fleming ID, Fremgen AM, Menck HR (1998) A National Cancer Data Base report on 53,856 cases of thyroid carcinoma treated in the U.S 1985 Cancer 83 : 2638-2648. [Crossref]

3. Spencer CA, Wang CC (1995) Thyroglobulin measurement. Techniques, clinical benefits, and pitfalls. Endocrinol Metab Clin North Am 24: 841-863. [Crossref]

4. Aras G, Gültekin SS, Küçük NO, Genç Y (2007) Is thyroglobulin the stronger indicator for progressive disease than the other conventional factors in same age patient groups with differentiated thyroid cancer? Nucl Med Commun 28: 907-913. [Crossref]

5. Schlumberger M, Baudin E (1998) Serum thyroglobulin determination in the followup of patients with differentiated thyroid carcinoma. Eur J Endocrinol 138: 249-252. [Crossref]

6. Roelants V, Nayer PD, Bouckaert A, Beckers C (1997) The predictive value of serum thyroglobulin in the follow-up of differentiated thyroid cancer. Eur J Nucl Med 24: 722-727. [Crossref]

7. Sawka AM, Orlov S, Gelberg J, Stork B, Dowar M, et al. (2008) Prognostic value of postsurgical stimulated thyroglobulin levels after initial radioactive iodine therapy in well-differentiated thyroid carcinoma. Head Neck 30: 693-700. [Crossref]

8. Ronga G, Filesi M, Ventroni G, Vestri AR, Signore A (1999) Value of the first serum thyroglobulin level after total thyroidectomy fort he diagnosis of metastases from differentiated thyroid carcinoma. Eur J Nucl Med 26: 1448-1452.

9. Heemstra KA, Liu YY, Stokkel M, Kievit J, Corssmit E, et al. (2007) Serum 
thyroglobulin concentrations predict disease-free remission and death in differentiated thyroid carcinoma. Clin Endocrinol (Oxf) 66: 58-64. [Crossref]

10. Toubeau M, Touzery C, Arveux P, Chaplin G, Vaillant G, et al. (2004) Predictive value for disease progression of serum thyroglobulin levels measured in the postoperative period and after 131I ablation therapy in patients with differentiated thyroid cancer. $J$ Nucl Med 45: 988-994.

11. Gilliland FD, Hunt WC, Morris DM, Key CR (1997) Prognostic factors for thyroid carcinoma. A population-based study of 15,698 cases from the Surveillance, Epidemiology and End Results (SEER) program 1973-1991. Cancer 79: 564-573. [Crossref]

12. Haugen BR, Alexander EK, Bible KC, Doherty GM, Mandel SJ, et al. (2016) 2015 American Thyroid Association Management Guidelines for Adult Patients with Thyroid Nodules and Differentiated Thyroid Cancer: The American Thyroid Association Guidelines Task Force on Thyroid Nodules and Differentiated Thyroid Cancer. Thyroid 26: 1-133. [Crossref]

13. Pacini F, Schlumberger M, Dralle H, Elisei R, Smit JW, et al. (2006) European consensus for the management of patients with differentiated thyroid carcinoma of the follicular epithelium. Eur J Endocrinol 154: 787-803. [Crossref]

14. British Thyroid Association RcoP (2007) Guidelines for the management of thyroid cancer. 2nd edition. London:Royal College of Physicians.

15. Cady B, Rossi R (1988) An expanded view of risk-group definition in differentiated thyroid carcinoma. Surgery 104: 947-953. [Crossref]

16. Sherman SI, Brierley JD, Sperling M, Ain KB, Bigos ST, et al. (1998) Prospective multicenter study of thyrois]carcinoma treatment: initial analysis of staging and outcome. National Thyroid Cancer Treatment Cooperative Study Registry Group. Cancer 83: 1012-1021.

17. Mazzaferri EL (1999) An overview of the management of papillary and follicular thyroid carcinoma. Thyroid 9: 421-427. [Crossref]

18. Simpson WJ, McKinney SE, Carruthers JS, Gospodarowicz MK, Sutcliffe SB, et al. (1987) Papillary and follicular thyroid cancer. Prognostic factors in 1,578 patients. $\mathrm{Am}$ $J$ Med 83: 479-488. [Crossref]

19. Ceccarelli C, Pacini F, Lippi F, Elisei R, Arganini M, et al. (1988) Thyroid cancer in children and adolescents. Surgery 104: 1143-1148. [Crossref]

20. Schlumberger M, De Vathaire F, Travagli JP, Vassal G, Lemerle J, et al. (1987) Differentiated thyroid carcinoma in childhood: long term follow-up of 72 patients. $J$ Clin Endocrinol Metab 65: 1088-1094. [Crossref]

21. Zimmerman D, Hay ID, Gough IR, Goellner JR, Ryan JJ, et al. (1988) Papillary thyroid carcinoma in children and adults: long-term follow-up of 1039 patients conservatively treated at one institution during three decades. Surgery 104: 1157-1166. [Crossref]
22. Shaha AR, Shah JP, Loree TR (1996) Risk group stratification and prognostic factors in papillary carcinoma of thyroid. Ann Surg Oncol 3: 534-538. [Crossref]

23. Segal K, Raveh E, Lubin E, Abraham A, Shvero J, et al. (1996) Well-differentiated thyroid carcinoma. Am J Otolaryngol 17: 401-406. [Crossref]

24. Hay ID (1990) Papillary thyroid carcinoma. Endocrinol Metab Clin North Am 19: 545 576. [Crossref]

25. Ruegemer JJ, Hay ID, Bergstralh EJ, Ryan JJ, Offord KP, et al. (1988) Distan metastases in differentiated thyroid carcinoma: a multivariate analysis of prognostic variables. J Clin Endocrinol Metab 67: 501-508. [Crossref]

26. Cunningham MP, Duda RB, Recant W, Chmiel JS, Sylvester JA, et al. (1990) Surviva discriminants for differentiated thyroid cancer. Am J Surg 160: 344-347. [Crossref]

27. Mazzaferri EL, Jhiang SM (1994) Long-term impact of initial surgical and medica therapy on papillary and follicular thyroid cancer. Am J Med 97: 418-428. [Crossref]

28. Machens A, Hinze R, Thomusch O, Dralle H (2002) Pattern of nodal metastasis for primary and reoperative thyroid cancer. World J Surg 26: 22-28. [Crossref]

29. Lundgren CI, Hall P, Dickman PW, Zedenius J (2006) Clinically significant prognostic factors for differentiated thyroid carcinoma: a population-based, nested case-control study. Cancer 106: 524-531. [Crossref]

30. Frankenthaler RA, Sellin RV, Cangir A, Goepfert H (1990) Lymph node metastasis from papillary-follicular thyroid carcinoma in young patients. Am J Surg 160: 341-343. [Crossref]

31. Carcangiu ML, Zampi G, Pupi A, Castagnoli A, Rosai J (1985) Papillary carcinoma of the thyroid. A clinicopathologic study of 241 cases treated at the University of Florence, Italy. Cancer 55: 805-828. [Crossref]

32. Hall FT, Beasley NJ, Eski SJ, Witterick IJ, Walfish PG, et al. (2003) Predictive value of serum thyroglobulin after surgery for thyroid carcinoma. Laryngoscope 113: 77-81. [Crossref]

33. Lin JD, Huang MJ, Hsu BR, Chao TC, Hsueh C, et al. (2002) Significance of postoperative serum thyroglobulin levels in patients with papillary and follicular thyroid carcinomas. J Surg Oncol 80: 45-51. [Crossref]

34. Vaisman A, Orlov S, Yip J, Hu C, Lim T, et al. (2010) Application of post-surgica stimulated thyroglobulin for radioiodine remnant ablation selection in low-risk papillary thyroid carcinoma. Head Neck 32: 689-698. [Crossref]

35. Nascimento C, Borget I, Ghuzlan A, Deandreis D, Chami L, et al. (2011) Persisten disease and recurrence in differentiated thyroid cancer patients with undetectable postoperative stimulated thyroglobulin level. Endocr Relat Cancer 18: 29-40.

36. Rosario PW, Xavier AC, Calsolari MR (2011) Value of postoperative thyroglobulin and ultrasonography for the indication of ablation and ${ }^{131} \mathrm{I}$ activity in patients with thyroid cancer and low risk of recurrence. Thyroid 21: 49-53. [Crossref]

Copyright: (C2017 Ozkan E. This is an open-access article distributed under the terms of the Creative Commons Attribution License, which permits unrestricted use, distribution, and reproduction in any medium, provided the original author and source are credited. 